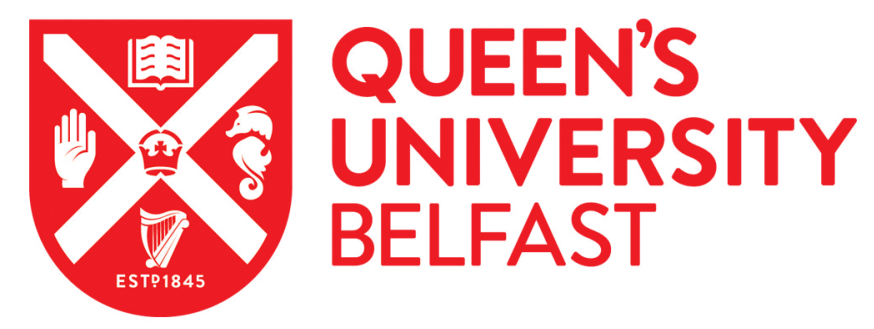

\title{
Building partnerships in social work education: Towards achieving collaborative advantage for employers and universities
}

Wilson, G. (2014). Building partnerships in social work education: Towards achieving collaborative advantage for employers and universities. Journal of Social Work, 14(1), 3-22. https://doi.org/10.1177/1468017313475547

Published in:

Journal of Social Work

Document Version:

Peer reviewed version

Queen's University Belfast - Research Portal:

Link to publication record in Queen's University Belfast Research Portal

\section{Publisher rights}

Copyright The Author 2013.

This is an accepted manuscript of an article published in the Journal of Social Work, available in final version at doi:10.1177/1468017313475547

\section{General rights}

Copyright for the publications made accessible via the Queen's University Belfast Research Portal is retained by the author(s) and / or other copyright owners and it is a condition of accessing these publications that users recognise and abide by the legal requirements associated with these rights.

Take down policy

The Research Portal is Queen's institutional repository that provides access to Queen's research output. Every effort has been made to ensure that content in the Research Portal does not infringe any person's rights, or applicable UK laws. If you discover content in the Research Portal that you believe breaches copyright or violates any law, please contact openaccess@qub.ac.uk. 


\title{
Building partnerships in social work education: Towards achieving collaborative advantage for employers and universities.
}

\section{George Wilson, Queen's University, Belfast}

\begin{abstract}
Summary: Better partnership working between employers and academic institutions has recently been identified as one of the key developments needed to improve social work education and practice in the UK (Social Work Reform Board, 2010). However, the praxis of collaborative working in social work education remains under-researched and it is unclear what factors are significant in promoting effective partnership. This article contributes to this debate by reporting research that examined the experience of social work academics working with employers to deliver qualifying level social work education in Northern Ireland.
\end{abstract}

Findings: This analysis explores key factors in the dynamics of the collaborative process and identifies both congruence and discord in academic and employer perspectives. The findings highlight the collaborative advantage accruing from partnership working, which include the benefits of a centrally coordinated system for the management and delivery of practice learning. However, the results also indicate that engaging in partnership working is a complex process that can create conflict and tensions, and that it is important to ground collaborations in realistic expectations of what can be achieved. Application: This article identifies opportunities for achieving collaborative advantage and the challenges. It identifies lessons learned about the value of partnership working in social work education and ways to increase its efficacy.

Keywords: Social work, social work education, collaboration, curriculum development 


\section{Introduction}

Social work in the UK is currently experiencing major change in the wake of a succession of critical reviews of social work performance (Laming, 2003; Munro, 2011; Social Work Reform Board, 2010). Developing better partnership working between Universities and employing agencies has been highlighted as a key goal among a range of proposals for improving both social work education and practice standards (Social Work Reform Board, 2010). It has been assumed in such documents that better collaborative working will not only help to improve the content of education and quality of practice learning provision but also will assist in the creation of a more comprehensive framework for continuing professional development and workforce planning in social work (Social Work Reform Board, 2010). The concepts of 'partnership' and 'collaboration' have been major themes underpinning the delivery of health and social care in the UK for many years and it is perhaps unsurprising that they have now emerged as key principles in the process of reform taking place in social work education (Glendinning, 2002; Lymbery, 2006; Social Work Reform Board, 2010). However, although the scope of the proposed reforms have significant implications for both Universities and employers, it is uncertain both whether these distinct interest groups share a common vision about what needs to be done to improve practice and educational provision and also to what extent they will be able to develop effective partnerships and work together to progress the proposed reforms (Munro, 2011; Social Work Reform Board, 2010).

Whilst considerable faith has been placed in the potential advantages of partnerships between Universities and employers, this area is under-researched (McLaughlin, Shardlow, Brettles, Coleman, \& Glover, 2010; Munro, 2010). The few previous studies of partnerships between Universities and employers in the UK indicate that collaborative working is generally underdeveloped and characterised by a lack of consistency in approach (McLaughlin et al., 2010). This article aims to contribute to current debate by reporting 
research into the experience of social work academics of working in partnership with employing agencies to provide qualifying level social work education in Northern Ireland. This study was part of a larger pilot project completed in 2010 that examined the academic role and contribution to social work education of the two Universities in Northern Ireland, that is, Queen's University Belfast and the University of Ulster. The main aim of this part of the project was to explore academic perceptions of partnership working in order to develop understanding of the factors that might facilitate or inhibit effective collaboration and achievement of the type of improvements to educational outcomes envisioned by the Munro Review (Munro, 2011).

The article begins with a brief review of the literature on inter-organizational partnership working focusing in particular on Huxham and Vangens' (2005) theory of collaborative advantage, which is used in the analysis as a conceptual framework to explore the complex interrelationships between Universities and employing agencies in Northern Ireland. The following sections then outline the research context and methodology and report on the key findings relating to social work academics' experience of partnership working with employers. The final part of the article considers to what extent the findings are consistent with Huxham and Vangen's theory and draws on related research studies to highlight both the challenges and the opportunities for achieving collaborative advantage in developing social work education and practice. Whilst the study focused on the Northern Ireland context, the findings are relevant to inform debate about the value and efficacy of partnership working in social work education in other parts of the UK and internationally.

\section{Partnership Working and Collaborative Advantage}

Huxham and Vangen’s (2005) theory of collaborative advantage provides a useful framework for understanding and analysing partnerships as it is a multifaceted construction, which 
encompasses the broad range of themes and activities and hopes and expectations for collaborative working that have been mapped out by the Social Work Reform Board (2010). Huxham and Vangen (2005) argue that the purpose of collaboration is to achieve collaborative advantage, which is concerned with developing synergy between organisations and refers to any activity that involves working across organisational boundaries towards common goals individual agencies could not achieve on their own. Huxham and Vangen (2005) suggest a number of common bases relevant to most collaborative partnerships including, access to resources, achieving improved efficiency, seamlessness and coordination, securing access to a greater range of resources, risk sharing and providing opportunities for mutual learning. In the case of social work education it is assumed that Universities as providers would be unable to achieve all the objectives for professional social work education using only their own resources and have an incentive to collaborate with employing agencies, for example, to secure the provision of high quality practice learning opportunities for students (Social Work Reform Board, 2010). Huxham and Vangen (2005, p. 7) also stress that a 'moral imperative' may be one of the most important reasons for organisations to collaborate as many important social issues cannot be tackled by organisations acting alone. Arguably, the 'moral imperative' has a particular significance in social work as a justification for collaborative working between Universities and employers given the value base of the profession and the challenges involved in working to empower service users, promote social justice and safeguard the most vulnerable members of our society (Social Work Reform Board, 2010). In essence, the advantages of Universities and employing agencies working in partnership to facilitate a seamless and consistent approach towards the achievement of common social work educational goals seem self-evident. 
However, evaluating the effectiveness of collaborative partnerships presents formidable methodological challenges, including problems with attribution, causality and cost-benefits analysis (Dowling, Powell, \& Glendinning, 2004; El Ansari, Phillips, \& Hammick, 2001). Whilst nuanced distinctions can be made between the terms 'partnership' and 'collaboration', these concepts lack clear and uncontested definitions (Glendinning, 2002; Lymbery, 2006; Miller \& Ahmad, 2000; Social Work Reform Board, 2010). Another problem for researchers is that 'partnership' and 'collaboration' encompass such a wide variety of factors that impact on both process and the achievement of outcomes, including, for example, the nature of aims and objectives, trust and legitimacy, power, leadership, governance arrangements, resources, staff commitment, interpersonal relationships, organisational culture and communication (Dowling et al., 2004; El Ansari et al., 2001; Lasker, Weiss, \& Miller, 2001; Vangen \& Huxham, 2003). In addition to the multifactorial nature of the concepts involved the timing of evaluation (for example, whether to evaluate short or long-term effects) also contribute to making measurement of effectiveness problematic (Balloch \& Taylor, 2001). Nevertheless, given the hopes and expectations for collaborative working between Universities and employers in social work education (and the time and resources likely to be required to develop this enterprise), it is important to develop understanding and learn from experience of how such processes work in practice.

\section{Research Context}

Northern Ireland provides an interesting case study of partnership working given its long tradition of collaboration between employers and its two University providers, Queen's University Belfast (QUB) and the University of Ulster (UU) in the delivery of social work education (Bamford, 1996; Taylor, Mullineux, \& Fleming, 2010; Wilson \& Kelly, 2010). Following the introduction of a new undergraduate degree as the entry level qualification to 
the social work profession in 2004, existing collaborative relationships were formally reconstituted with the creation of a Northern Ireland Degree in Social Work Partnership (commonly known as the Degree Partnership) with regional responsibility for ensuring a consistent approach to the planning and delivery of qualifying level education. The role of the Degree Partnership in Northern Ireland appears in harmony with the vision for partnerships outlined by the Social Work Reform Board (2010) as it covers a broad spectrum of functions including regional systems for practice learning allocation, student admissions, and quality assurance of educational provision (McLaughlin et al., 2010; NIDSWP, 2010). Figure 1 outlines the Degree Partnership's committee structures and institutional relationships with other stakeholders involved in the delivery of social work education in Northern Ireland.

The various committees are run jointly by academics from both of Northern Ireland's Universities and staff from Health and Social Care Trusts and a range of voluntary sector employers. A distinctive feature of the Northern Ireland collaborative arrangements is that both the government department responsible for commissioning educational provision, the Department of Health and Social Services and Public Safety (DHSSPS) and the regulating authority, the Northern Ireland Social Care Council (NISCC) are also represented on the regional Degree Partnership Delivery Committee (see Figure 1). In addition to the Degree Partnership’s regional structures each of Northern Ireland's Universities has retained internal partnership arrangements for managing the planning, design, delivery and evaluation of course provision. Internal partnership arrangements have evolved separately alongside the Degree Partnership as a consequence of different legal and structural arrangements for the delivery of social work education in each University. In the case of QUB, for example, the Collaborative Partnership at Queen's (CPAQ) also includes academic staff, employers, service users and carers, students and a representative from NISCC. 


\section{Figure 1.}

\section{Northern Ireland Degree in Social Work Partnership.}

Northern Ireland currently produces over 200 social work graduates annually and the Degree Partnership has a key role to promote consistency of educational standards across both Universities and employing agencies. For example, the Degree Partnership was responsible for establishing a uniform approach by both QUB and UU towards the teaching and assessment of students' preparedness for undertaking practice learning (Wilson \& Kelly, 2010). The Degree Partnership's role in coordinating practice learning allocation and provision involves ensuring that agencies provide a set quota of placements to quality standards agreed with NISCC and the DHSSPS. In Northern Ireland, these quality standards, for example, include the requirement that practice learning opportunities must be delivered by qualified social workers who hold a post-qualifying award in practice teaching (NIDSWP, 2010; NISCC, 2007).

The social work curriculum in Northern Ireland is similar to social work courses elsewhere in the UK as it is based on national occupational standards (NISCC, 2003). Both QUB and UU programmes provide a mix of generic and specialist academic taught content combined with two practice learning opportunities of 85 and 100 days in the first and final year of the degree respectively (NISCC, 2003). Like other parts of the UK, Northern Ireland has recently experienced child care tragedies that have strongly affected social work and tarnished the public image of the profession (Department of Health, Social Services and Public Safety, 2009). In response to public concerns, government policy in relation to social work has increasingly focused on regulation of the profession and maintaining performance 
standards including adherence to policies and procedures (Heenan, 2004; Munro, 2010). The Degree Partnership has responsibility for ensuring that the social work curriculum is relevant and up to date and students who graduate are equipped with the requisite skills, knowledge and values to practise effectively.

\section{Research Aims}

The article reports on academics' perceptions of both the process and outcomes of collaborative working with NIDSWP agency partners. The specific aims of the research were:

- To examine academic staff experience of collaborative working and relationships with agency colleagues involved in NIDSWP.

- To identify academic staff perceptions of the strengths and limitations of NIDSWP and current partnership arrangements for the management and delivery of social work education including practice learning provision.

- To consider the implications of the findings for partnership working between Universities and employers and the opportunities for and challenges to achieving collaborative advantage.

\section{Methodology}

The project used a mixed methodological approach consisting of a questionnaire and focus groups to find out academic staff perceptions of collaborative working with employing agency partners in Northern Ireland. This approach was chosen as using quantitative and qualitative methods simultaneously would enhance data collection and analysis and ultimately increase validity of the findings (Lindgard, Albert, \& Levinson, 2008). As 
Northern Ireland has only two Universities involved in social work education, gathering and analysing the data from a joint QUB/UU perspective provided a greater degree of anonymity to individual respondents.

\section{Questionnaire}

Academic social work staff from both QUB and UU institutions were invited to complete a questionnaire to elicit quantitative and qualitative data in relation to the research aims $(n=36)$. The questionnaire included mainly closed, pre-coded questions but also incorporated open-ended questions which allowed academic staff to add comments. Respondents, for example, were asked to report on their perceptions of the strengths and limitations of relationships with agency partners and their evaluation of the efficiency and effectiveness of Degree partnership structures and processes. Staff were also asked about their satisfaction with social work education including practice learning and to what extent the curriculum content of programmes addressed the educational goals they believed were important. The questionnaire used in the project was piloted with a group of social work academic colleagues (not from QUB or UU) who participated with the author in an Economic and Social Research Council sponsored Learning Set. Some minor amendments were made to the original questionnaire following feedback from this group. As Universities tend to have a range of staff involved in qualifying level social work education, it was decided to define academic staff in this study as any full or part-time staff with the title of social work lecturer, including senior lecturers and professors.

The questionnaire was administered via email to staff in both institutions simultaneously. In a study that compared postal and web-based questionnaires, researchers found that the 
response rate for the online questionnaire was significantly higher than that recorded for the postal equivalent (Cobanoglu, Ward, \& Moreo, 2001). In the present study, the questionnaire, together with an explanatory email, was forwarded on one occasion to all academic staff in each institution with two follow-up emails. A response rate of $75 \%$ was achieved with a total of 27 questionnaires returned. Quantitative data from the survey were inputted into the SPSS computer software package for statistical analysis. Interpretive validation techniques were used to analyse the qualitative data that emerged from open-ended questions in the questionnaire and these were then organised to illustrate common and divergent themes using selected quotations.

\section{Focus groups}

Nine social work academics from QUB and 13 from UU who had completed questionnaires agreed to participate in two separate focus groups held in different locations. An analysis of the questionnaire findings was used to select the themes for the focus group topic guide. The aim of focus group sessions was to further explore the quantitative findings from the questionnaires through allowing staff to elaborate on their opinions and explore the meanings they attached to particular answers (Krueger \& Casey, 2005). Focus group sessions were digitally recorded with staff consent. During the sessions, respondents were given an opportunity to initiate discussion of new topics based on their experience of partnership working with employers. This helped to ensure that respondents were given as much opportunity as possible to express their views about both the strengths and limitations of collaborative working. The NVivo computer package for qualitative research was used to analyse transcribed data from the focus groups, identify common themes that linked with questionnaire findings and create new themes based on respondents' experience. 


\section{Findings}

The major themes relating to collaborative working between Universities and employers that emerged from the research are discussed below. In addition to the demographic characteristics of respondents this section reports on academic perspectives in relation to the following areas: degree curriculum; practice learning standards and partnership arrangements; collaborative working within NIDSWP management and committee structures.

\section{Demographic characteristics}

The respondents in this study were a very experienced group with an average time spent in the social work education sector of 11 years with a maximum of 30 years. Each respondent had a professional social work qualification and at least three academic qualifications including a $\mathrm{PhD}$ or DPhil (52\%) and/or a Masters (63\%). In addition, a significant number had professional post-qualifying awards in social work, including the Advanced Award (37\%) and the Practice Teaching Award (37\%). The age range of the cohort was from 30 to 63 years and $67 \%$ of the sample was male and $33 \%$ female. The majority of staff were employed as lecturers (63\%) or senior lecturers (22\%). A substantial proportion of the cohort had experience of social work practice with more than one service user group and averages were calculated according to years spent within a specific sector. For example, a large majority (70\%) had worked in a family and childcare setting with an average time in practice of 7.5 years. Forty-eight per cent of staff had also worked in mental health settings with an average across the group of 6.2 years in practice. The findings indicated that, in addition to lecturing and tutoring, staff carried out a wide variety of internal and external administrative roles. All staff had direct experience of partnership working with agency colleagues, most commonly in the admissions process and servicing practice learning opportunities. A number 
of staff also had experience of working with agency colleagues on NIDSWP management bodies, committees and working groups.

\section{Perspectives on degree curriculum}

Respondents were asked to report how satisfied they were with the curriculum. Whilst nearly half of academic staff (44\%) were satisfied or very satisfied, Table 1 indicates that a significant number of respondents were unsure about or dissatisfied with programme content.

\section{Table 1.}

\section{Satisfaction with the degree programme curriculum.}

When these results were explored further, it was found that staff were satisfied or very satisfied with most aspects of the taught curriculum particularly law (82\%), family and child care (81\%) and criminal justice (73\%). Satisfaction levels were significantly lower in areas of adult social care such as mental health and physical disability (with only $30 \%$ of staff satisfied or very satisfied in both areas). Qualitative feedback from focus groups suggested that differences in satisfaction levels with the taught curriculum in these areas were mainly a function of staff interests and expertise. For example, as one staff member explained:

I think it's also because in part when you look at your practice experience or the research interests, a large proportion of staff activity is around family and childcare. 
However, the results also indicated that many respondents were dissatisfied with other core elements of teaching and learning. For example, only $36 \%$ of respondents felt that social justice was satisfactorily integrated into the curriculum and $48 \%$ were dissatisfied with teaching and learning in relation to critical reflection. Qualitative comments from focus group respondents were mainly negative about both these aspects of teaching and learning. Comments seemed to reflect differences between what respondents felt were 'educational' priorities in relation to promoting critical reflection and social justice and employer priorities dominated by a 'training' agenda concerned with the functional needs of agencies for workers skilled in following policies and procedures.

I think we're training people to be professionals ... at a critical and analytical level, whereas the great pressure on an agency is performance-indicated activity that is in relation to a set of procedures and guidelines.

Some respondents commented on how particular areas of social work practice where links could be readily made to social justice issues, including, for example, community work and community development, were receiving less priority within the new degree. A number of academics also acknowledged the tension of trying to instil commitment to critical reflection and social justice whilst at the same time ensuring student preparedness to work within agency policies and procedures and within a climate of increasing resource constraint:

I think there are tensions there, because on the one hand we want them to be fit for agency practice and on the other ... we want them to resist but we 
don't know how to tell them to do this.

\section{Practice learning standards and partnership arrangements}

Over two thirds of respondents (70\%) were satisfied or very satisfied with their working relationships with agency practice teachers and only $7 \%$ expressed dissatisfaction. Respondents were also asked to rate the practice learning component of the social work degree. As indicated in Table 2, nearly half of respondents (48\%) felt that the practice learning component of the degree was good or excellent.

\section{Table 2}

\section{Ratings for the practice learning component of the degree.}

Qualitative data from respondents in both the questionnaire and focus group sessions highlighted a number of positive features of the practice learning model in Northern Ireland, including the requirement for staff who supervise students to hold a recognised professional qualification in practice teaching:

Student feedback is generally very positive and the impression gathered from visiting placements for reviews suggests high quality. I believe the standard has risen since the introduction of the Practice Teacher Award.

Only $11 \%$ of staff thought practice learning was poor or very poor. However, in qualitative comments in questionnaire respondents reported variability in the quality of practice learning opportunities (PLOs) and their experience of situations in which placement 
limitations had negatively impacted on student learning - particularly in relation to reflective practice skills. Typical comments included the following:

I believe some placements are very good, primarily due to the input that good practice teachers are able to provide. However, some practice teachers are not able to support students appropriately in terms of theory or reflective development.

There was a strong consensus across both focus groups that practice learning environments had become increasingly dominated by a bureaucratic-instrumental bias and an over-reliance on proceduralised forms of practice that respondents felt tended to reflect the priorities and concerns of agency partners and NISSC.

I know from previous students they are shocked by the heavily proceduralized, target-driven nature of the post-qualifying social work world they have to live in.

In identifying the factors that inhibited the development of critically reflective practice, some respondents acknowledged that academic staff could do more to challenge the functionalist bias within practice learning environments:

We have to toe along with functionalists and our views are slightly sidelined a bit; It's our own fault because we don't get in there a lot.

\section{Collaborative working within NIDSWP management and committee structures}

More than three quarters of respondents (78\%) reported that they were satisfied or very satisfied with relationships with agency partners on the various NIDSWP committees and management groups (See Table 3). When asked to rate the effectiveness of collaborative 
partnership arrangements, a majority of respondents (60\%) reported that the regional structures supporting the NIDSWP were effective.

\section{Table 3.}

Satisfaction with relationships with agency partners.

A number of respondents (19\%) also commented positively in the questionnaire on the long tradition of collaborative working with employers in Northern Ireland and felt partnership arrangements and relationships had promoted high quality education and achieved good learning outcomes:

The regional approach adopted in NI ensures consistency and promotes good quality education and learning. The structures are in my view effective in terms of achieving good outcomes for students and service users.

Whilst recognising the advantages of collaborative working, a significant number of respondents (22\%) who felt the regional partnership arrangements were effective also acknowledged its limitations. Among the areas of concern reported were the time-consuming nature of involvement in committee work and unease about the overly centralised and complex bureaucratic nature of NIDSWP structures, which it was felt, tended to hamper decision making and achieving improvements to the curriculum. Comments included the following: 
Mainly effective but the system has become overly centralized and bureaucratic, which makes change difficult and may inhibit creativity and innovation.

Just over a quarter (26\%) of respondents in the questionnaire indicated that the regional partnership arrangements were ineffective. Qualitative comments from this group highlighted the difficulties of achieving consensus and a consequent tendency towards inertia and slow decision-making engendered by NIDSWP structures. Focus group commentary corroborated the view that NIDSWP was burdened by overly complex layers of bureaucracy that hampered decision-making:

They are very complex, which means that if you have to change something very simple you have to form a working group... so there are around 15 people who have to agree something is changed.

Whilst acknowledging the benefits of NIDSWP's quality assurance role, some respondents felt that the need to achieve standardisation across University and employer interests could present a barrier to innovation and lead to disharmony when there were differences in aims and priorities:

It becomes more disparate than harmonious and people are pulling in different directions... priorities are very different...you can feel that you are a lone voice.

Differences were noted in the way University and employer representatives viewed the status of NIDSWP activities and some respondents felt academic staff needed to give participation in committee work a greater priority to ensure their voice was heard: 
I definitely think there's a status thing as well; there's a very high status for trainers (employed in staff development teams) to be populating those things but for us, we have some other agendas.

A number of respondents also pointed out that the absence of a collaborative partnership relationship between Universities and employers would present greater problems for delivering effective social work education:

The problems on the other side without [partnerships] are much greater; having no relationship gives you a whole different set of problems.

\section{Discussion}

The Northern Ireland Degree in Social Work Partnership appears to have many of the characteristics that Huxham and Vangen (2005) identify as essential for securing collaborative advantage. The Degree Partnership features the type of formally contracted collaborative arrangements for planning, delivering and quality assuring social work education (including the selection of students and the allocation and supply of practice learning) that the Social Work Reform Board (2010) propose should be established throughout the UK (NIDSWP, 2010). However, although the results suggest that the Degree Partnership is generally effective and Universities and employers share congruent interests in developing social work education, there were a number of areas where aims and priorities appeared to differ and partnership working presented a more problematic process of engagement. 
So what insights do the results provide about the process and the outcomes achieved by partnership working in Northern Ireland and what lessons can be taken from this research about the opportunities and challenges for achieving collaborative advantage in social work education? Firstly, in relation to outcomes, Lasker et al. (2001) have observed that one of the most important considerations in evaluating the effectiveness of collaborative partnerships is whether the investment in time and resources is warranted and likely to achieve better results than efforts by single agencies working on their own. The results of this study suggest that most respondents believed the regional management and committee structures offered advantages in providing effective mechanisms for achieving high quality standards of provision and educational outcomes that could not be delivered by either partner working independently. In this context, employers and Universities clearly have synergy of interests and share a mutual desire to ensure that social work students achieve the best possible preparation for practice (Huxham \& Vangen, 2005).

Respondents were particularly satisfied with the ability of collaborative arrangements in Northern Ireland to deliver high quality standards of practice learning, which is one of the main areas in which the Reform Board expect better partnership working will facilitate enhanced outcomes (Social Work Reform Board, 2010). The regional system for delivering practice learning in Northern Ireland provides an effective mechanism for joint decisionmaking about placement allocation and ongoing quality assurance of provision. The findings indicate that guaranteed access to agency resources through a regionally managed and centrally coordinated system is perhaps one of the major strengths of the type of collaborative arrangements developed by the Degree Partnership. A number of respondents highlighted that another advantage of the Northern Ireland system, which, unlike some other parts of the UK, the Degree Partnership has been able to retain, is a commitment to ensuring that all practice 
teachers are both qualified social workers and hold a post-qualifying award in practice teaching (Orme et al., 2009; Wilson \& Kelly, 2010).

Huxham and Vangen (2005) caution that stakeholders usually bring to partnerships different priorities, ideologies and cultures and in consequence agreeing joint aims, sharing power and developing trust can present significant obstacles to either collaborating at all or achieving any real progress. Whilst there are opportunities for partnership working to be highly productive, clearly, there is also scope for divergence and lack of consistency between Universities and employers about educational aims and objectives and partners gaining less collaborative advantage than might otherwise be possible to achieve. Conflicts in collaborative working can also emerge if partnerships adopt proposals that contradict the selfinterest of an individual organisation or do not address their concerns (Lotia \& Hardy, 2008; Miller \& Ahmad, 2000). Perhaps one of the most significant issues to emerge from this study was respondents' perception that the aims and priorities of the Degree Partnership focused more on functionalist and instrumental concerns and less on educational outcomes which academics considered important. For example, the results indicated that academic staff in Northern Ireland have not always agreed with agency priorities and have wished for there to be more emphasis in social work education on producing students skilled in critical reflection and committed to promoting social justice. Nevertheless, University and agency partners involved in the Degree Partnership seem to have been able to gain a degree of collaborative advantage in achieving educational outcomes by adopting a pragmatic approach and making progress in those areas where they have been able to agree, including practice learning allocation and provision. 
Overall, from the perspective of academic staff, the findings suggested that the Degree Partnership has been driven by priorities employers considered most important in relation to educational outcomes. The view that the Degree Partnership's priorities reflect a 'training' agenda and centre on the need to produce workers competent in following policy and procedures resonates with the Munro Review findings that agencies in the UK have become dominated by a bureaucratic-instrumental bias (Munro, 2011). This finding would tend to support the view that an over-emphasis on procedurally driven practice is deeply ingrained in agency working cultures and that the attitudes and beliefs underpinning such practices are likely to present formidable obstacles to developing the type of culture of critical reflection, which Munro (2011), for example, has argued is essential for improving social work practice and decision making (Wilson, 2011). Critical reflection is also a contested concept and it is uncertain whether Universities and employers involved in local partnerships in different parts of the UK will share the same view about what it means and how it should be operationalised in social work education and practice (Fook, 2004). Nevertheless, the educational goals of Universities and employers are not necessarily mutually exclusive and they share a common aspiration to produce qualified social workers who are both skilled in critical reflection and competent to work within agency policy and procedures. The current reform process and proposals for better collaborative partnerships provide a vehicle and an opportunity for Universities and employers to engage in dialogue about how best to achieve common educational goals and improve the curriculum (Munro, 2011; Social Work Reform Board, 2010).

The results indicated that one of the most significant concerns expressed by respondents about the process of partnership working focused on what Huxham and Vangen (2005) have termed 'collaborative inertia' which tends to arise when those participating in collaborations 
experience frustration and/or lack of progress in achieving aims that serves to undermine commitment. The main sources of potential collaborative inertia emerging from this study surrounded the complex bureaucratic structures of the Degree Partnership, which from the perspective of respondents involved duplication of effort, were time-consuming to service and created obstacles that inhibited creativity and innovation. Respondents' frustration with the process of collaborative working within the Degree Partnership’s interlocking committee structures stemmed from a belief that these systems were resistant to change, a view that may have been reinforced by a perception of asymmetry in power relations between Universities and employers. According to Huxham and Vangen (2005) asymmetries in power (both real and imagined) and suspicion rather than trust are often the norm in partnership working relationships and can lead to inertia and engender conflict.

The findings from this study suggest that the process of collaborative working may present significant challenges for University staff (and employer representatives) who have had little previous experience of the type of formally constituted partnerships being proposed by the Reform Board (Social Work Reform Board, 2010). It has been observed that engaging in partnership working may result in participants experiencing a number of disadvantages including loss of flexibility, control and extra resource costs (Gray \& Schruijer, 2010; Huxham \&Vangen, 2005). The results of this study indicate that significant numbers of respondents not only found the process of partnership working frustrating but also disempowering. Disparities in experience and the resources that different stakeholders are prepared to invest in partnership working can also adversely affect the process of collaborative working (Vlaar, Bosch, \& Volberda, 2006). The findings suggest that a sense of collaborative inertia among respondents may have arisen because of differences in perspective about the way partnership involvement was valued by University staff in 
comparison to agency partners. In short, given the pressures of managing other conflicting institutional priorities and demands on their time, not least in relation to research, academic staff may have been less able or willing to devote time and energy to collaborative partnership working. This suggests that in developing partnerships in social work education it is essential for both Universities (and employing organisations) to acknowledge the importance of staff involvement and be willing to commit the resources necessary to enable partnerships to work effectively (Social Work Reform Board, 2010).

Universities and employers in Northern Ireland are required by government and the regulating authority to work together in delivering social work education (NIDSWP, 2010). Northern Ireland is a small country and its size allows for its two Universities, a wide range of employers from the statutory and voluntary sectors and the commissioning and regulating authorities for social work education to be represented on the regional Degree Partnership. Involvement of key stakeholders clearly has the advantage of adding legitimacy and authority to the Degree Partnership's activities and decision making and helping to facilitate appropriate resource provision, not least in relation to practice learning. However, the system of partnership working in Northern Ireland has evolved over the years and a further distinctive feature of local arrangements is that in addition to the regional structures each University has retained its own internal partnership committees which involve other stakeholders. The frustrations expressed by respondents in this study with what they perceived as the complex and bureaucratic nature of partnership arrangements in Northern Ireland suggests there may be scope for streamlining structures and underlines the need to ensure that partnership systems are regularly reviewed to ensure they remain fit for purpose. 
Whilst it would be difficult to replicate the Northern Ireland structures in other parts of the UK, particularly in situations where there are much greater numbers of Universities and agencies, it might be possible to establish regional authorities similar to the Degree Partnership. Although partnerships will be mandatory, the Reform Board have rightly emphasised the importance of flexibility in establishing specific arrangements between Universities and employers and these are likely to differ depending on local needs and circumstances (Social Work Reform Board, 2010). One of the key lessons from this study is that while partnerships in social work education have many advantages the task of bringing together a wide range of stakeholder interests is not easy and presents challenges that may engender disadvantages. It is important that specific collaborative arrangements are designed to support effective decision making and facilitate efficient working relationships. A commitment to continuous improvement and the promotion of creativity and innovation in social work education are also essential to help minimise the possibility of collaborative inertia.

Irrespective of the type of partnership arrangements established, trust, as Bachman and Zaheer (2008) have observed, is a critical component of any collaboration and essential for ensuring effective collaborative working. One of the most significant findings from this study was respondents' high level of satisfaction with the quality of interpersonal relationships established with employer colleagues involved in the Degree Partnership and practice learning provision. This can be viewed as both a successful outcome as well as evidence of effective process. The long tradition of partnership in social work education has undoubtedly been an important factor in helping establish productive relationships and facilitating collaborative working in Northern Ireland (Bamford, 1996; Vangen \& Huxham, 2003). 


\section{Limitations}

Perhaps the main limitation of this study was that it focused on the perceptions of academic staff only and in consequence the nature of the findings reported are limited and tentative. A research project that also considered the views of employers and other key stakeholders, including representatives from the DHSS\&PS and NISCC involved in partnership working in Northern Ireland, would have provided a more comprehensive study. Dowling et al. (2004) have observed that partners can have quite divergent perspectives on to what extent the partnership has been successful in relation to both the process and the outcomes of collaborative working. Therefore, involving employers could have provided a more rounded picture of 'what works' within current arrangements and what aspects of partnership required further development.

Social work education in Northern Ireland takes place in a post-conflict situation and is therefore not fully comparable to other parts of the UK. For example, the educational curriculum includes consideration of the impact on social work of Northern Ireland's long legacy of political and sectarian conflict (Campbell \& Healey, 1999; Houston \& McCullough, 2001). Nevertheless, as mentioned previously, social work education in Northern Ireland is based on national occupational standards and curriculum content is very similar to other parts of the UK (Orme et al., 2009).

Finally, this was a small scale study of social work academic staff in two universities and cannot, therefore, claim to be representative of the views of academics in other parts of the UK or internationally. At the same time, the findings provide useful baseline data about academic perspectives on partnership working with employers and could be compared with related studies nationally and internationally. 


\section{Conclusion}

Overall, the results of this study endorse the view that partnerships between Universities and employer organisations can yield significant collaborative advantages in social work education. The findings highlighted the benefits that have resulted from the long tradition of partnership working in Northern Ireland and the positive relationships with agency partners that have evolved. Respondents particularly valued the collaborative regional arrangements in Northern Ireland for the management and delivery of practice learning, which they felt had helped to ensure high quality standards. However, the results indicated concerns that partnership priorities tended to reflect a ‘training' agenda dominated by agencies’ need to produce workers competent in following policy and procedures and were less focused on areas respondents considered important such as social justice and critical reflection. The findings provide evidence that developing effective collaborations and building trusting relationships can be a time-consuming and difficult process with no guarantee of successful outcomes. Nevertheless, the current review of social work in the UK has created fresh opportunities for Universities and employers to build a shared agenda around new initiatives such as developing critical reflection in education and practice. Whilst not a panacea, gaining collaborative advantage through better partnership working between Universities and employers clearly is an important step in the process of developing social work education.

\section{Ethics}

The research was approved by QUB Ethics Committee before the start of data collection.

\section{Acknowledgments}

This article was based on a SWAP (HEA)-funded research project. I also wish to thank Anne Campbell, my co-researcher in this project. 


\section{References}

Bachman, R., \& Zaheer, A. (2008). Trust in inter-organizational relations. In S. Cropper, M. Ebers, C. Huxham, \& P. S. Ring (Eds.), Oxford handbook of inter-organizational relations (pp. 533554). Oxford, England: Oxford University Press.

Balloch, S., \& Taylor, M. (Eds.) (2001). Partnership working: Policy and practice. Bristol: Policy Press.

Bamford, D. (1996). Partnership in social work education: A Northern Irish experience. International Journal of Educational Management, 10(3), 21-29. DOI:10.1108/09513549610115073.

Campbell, J., \& Healey, A. (1999). 'Whatever you say, say something’: The education, training and practice of mental health social workers in Northern Ireland. Social Work Education, 18 (4), 389-400. DOI: 10.1177/146801730505497.

Cobanoglu, C.,Ward, B., \& Moreo, P.J. (2001). A comparison of mail, fax and web survey methods. International Journal of Market Research, 43(4), 441-452.

Department of Health, Social Services and Public Safety (2009). Independent Review Report of Agency Involvement with Mr Arthur McElhill, Ms Lorraine McGovern and their children, Belfast, DHSS\&PS.

Dowling, B., Powell., M. \& Glendinning, C. (2004). Conceptualising successful partnerships, Health and Social Care in the Community, 12(4), 309-317. DOI: 10.1111/j.1365-2524.2004.00500.

El Ansari W., Phillips, C., \& Hammick, M. (2001). Collaboration and partnership: developing the evidence base. Health and Social Care in the Community, 9(4), 215-227. DOI: 10.1046/j.0966-0410.2001.00299. 
Fook, J. (2004). Critical reflection and transformative possibilities. In: L. Davies, \& P. Leonard (Eds.) Social work in a corporate era: practices of power and resistance. (pp. 1-10). Aldershot, Ashgate.

Glendinning, C. (2002). Partnerships between health and social services: Developing a framework for evaluation. Policy and Politics, 30(1), 115-127. DOI: 10.1332/0305573022501601.

Gray, B., \& Schruijer, S. (2010). Integrating multiple voices: Working with collusion in multiparty collaborations. In C. Stayaert, \& B. van Loy (Eds.), Relational practices: Participative organizing. (pp. 121-135). Bingley: Emerald Group Publishing.

Heenan, D. (2004). Learning the lessons from the past or re-visiting old mistakes: Social work and community development in Northern Ireland. British Journal of Social Work, 34(6), 793809. DOI: 10.1093/bjsw/bch102.

Houston., S. \& McCullough, W. (2001). Introduction. In S. Houston, V. McConvey, M. O'Rourke, \& M. Leonard (Eds.), Social work and innovation: An anthology of advanced level practice (pp.1-2). CCETSW, Belfast.

Huxham., C \& Vangen, S. (2005). Managing to collaborate: The theory and practice of collaborative advantage. Abingdon: Routledge.

Krueger, R. A., \& Casey, M. A. (2005). Focus groups: A practical guide for applied research. London, Sage.

Lord Laming (2003). The Victoria Climbie' Inquiry, Cm5730. London, The Stationery Office.

Lasker, R.D., Weiss, E.S., \& Miller, R. (2001). Partnership synergy: A practical framework for studying and strengthening the collaborative advantage. The Milbank Quarterly, 79(2), 179205. 
Lingard, L., Albert, M., \& Levinson, W. (2008). Grounded theory, mixed methods, and action research. British Medical Journal, 337, a567, 459-461. DOI: 10.1136/bmj.39602.690162.47.

Lotia, N., \& Hardy, C. (2008). Critical perspectives on collaboration. In S. Cropper, M. Ebers, C. Huxham, \& P.S. Ring (Eds.), Oxford handbook of inter-organizational relations (pp. 366389). Oxford, England: Oxford University.

Lymbery, M. (2006). United we stand? Partnership working in health and social care and the role of social work in services for older people. British Journal of Social Work, 36(7), 1119-1134. DOI: $10.1093 /$ bjsw/bch348.

McLaughlin H., Shardlow S.M., Brettles A., Coleman A., Glover A. (2010). Strengthening employer engagement in the planning, development and delivery of social work education. Retrieved 2 December 2011 from:

http://www.skillsforcare.org.uk/socialwork/research/social_work_research.aspx

Miller C., \& Ahmad Y. (2000). Collaboration and partnership: An effective response to complexity and fragmentation or solution built on sand? International Journal of Sociology and Social Policy, 20(5), 1-38. DOI: 10.1108/01443330010789151.

Munro, E. (2010). Learning to reduce risk in child protection. British Journal of Social Work, 40 (4), 1135-1151. DOI: 10.1093/bjsw/bcq024.

Munro, E. (2011). The Munro Review of Child Protection: Final Report - A child centred system. London: Department for Education.

NISCC (2003). The Reform of Professional Social Work Training: The Degree in Social Work in Northern Ireland. Belfast: Northern Ireland Social Care Council. 
NISCC (2007). The NISCC Designated Practice Learning Scheme. Belfast, Northern Ireland: Social Care Council.

NIDSWP (2010). Practice Learning Opportunities: Information for Students. Belfast: Northern Ireland Degree in Social Work Partnership.

Orme, J., MacIntyre, G., Lister, P. G., Cavanagh, K., Crisp, B., Hussein, S., Manthorpe, J., ... Stevens, M. (2009). What (a) difference a degree makes: The evaluation of the new social work degree in England. British Journal of Social Work, 39(1), 161-178. DOI: 10.1093/bjsw/bcm095.

Rogers, G. (1996). The voices of practice teachers in Britain \& Canada: comparing views after training. Issues in Social Work Education, 16(1), 2-27.

Sheehan, K. (2001). E-mail survey response rates: A review. Journal of Computer-Mediated Communication. 6(2). Retrieved 21 November 2011 from http://jcmc.indiana.edu/vol6/issue2/sheehan.html

Social Work Reform Board (2010). Building a Safe and Confident Future: One year on: Detailed proposals from the Social Work Reform Board. London: Department for Education.

Taylor, B. J., Mullineux, J., \& Fleming, G. (2010). Partnership, service needs and assessing competence in post qualifying education and training. Social Work Education, 29 (5), 475489. DOI: $10.1080 / 02615470903159117$.

Vangen, S., \& Huxham, C. (2003). Nurturing collaborative relations: Building trust in interorganizational collaboration. Journal of Applied Behavioral Science, 39(5), 5-31. DOI: 10.1177/0021886303039001001. 
Vlaar, P. W. L., Bosch, F. A. J., \& Volberda, H. W. (2006). Coping with problems of understanding in inter-organizational relationships: Using formalization as a means to make sense. Organization Studies. 27(11), 1617-1638. DOI: 10.1177/0170840606068338.

Wilson, G., \& Kelly, B. (2010). Evaluating the Effectiveness of Social Work Education: Preparing Students for Practice Learning. British Journal of Social Work, 40(8), 2431-2449. DOI: 10.1093/bjsw/bcq019.

Wilson, G. (2011). Evidencing Reflective Practice in Social Work Education: Theoretical Uncertainties and Practical Challenges. British Journal of Social Work, Available on advance access. DOI: 10.1093/bjsw/bcr170. 


\section{Northern Ireland Degree in Social Work Partnership}

(Structures, Functions and Relationships)

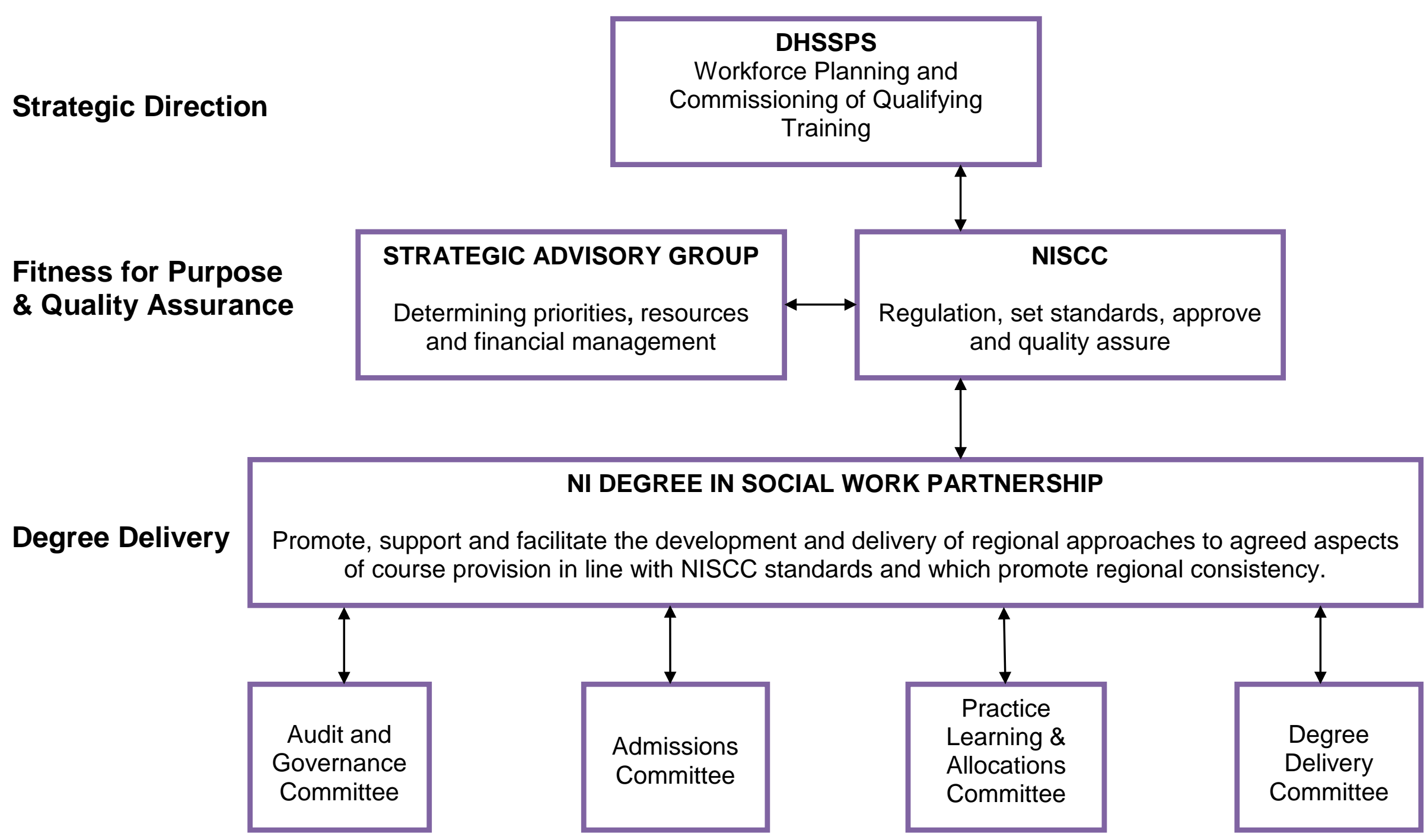


Table 1 Satisfaction with the degree programme curriculum

\begin{tabular}{|l|l|}
\hline $\begin{array}{l}\text { Satisfaction with the degree programme } \\
\text { curriculum }\end{array}$ & Percentage \\
\hline Dissatisfied & 19 \\
\hline Not sure & 30 \\
\hline Satisfied & 37 \\
\hline Very satisfied & 7 \\
\hline Missing & 7 \\
\hline
\end{tabular}


Table 2 Ratings for the practice learning component of the degree

\begin{tabular}{|l|l|}
\hline Ratings for the practice learning component of & Percentage \\
the degree & 4 \\
\hline Very poor & 7 \\
\hline Poor & 30 \\
\hline Average & 33 \\
\hline Good & 15 \\
\hline Excellent & 11 \\
\hline Missing & 4 \\
\hline System & \\
\hline
\end{tabular}


Table 3 Satisfaction with relationships with agency partners

\begin{tabular}{|l|l|}
\hline Satisfaction with relationships with agency & Percentage \\
partners & 4 \\
\hline Dissatisfied & 11 \\
\hline Not sure & 63 \\
\hline Satisfied & 15 \\
\hline Very satisfied & 7 \\
\hline Missing & \\
\hline
\end{tabular}

